DISTRIBUTION STATEMENT A. Approved for public release; distribution is unlimited.

\title{
Development of Novel Noninvasive Methods of Stress Assessment in Baleen Whales
}

\author{
Kathleen E. Hunt, Ph.D. (Lead PI) \\ Rosalind M. Rolland, D.V.M. (Co-PI), Scott D. Kraus, Ph.D. (Co-PI) \\ New England Aquarium \\ Central Wharf \\ Boston, MA 02110 \\ phone: (617) 226-2175 fax:(617) 973-0242 email: huntk@neaq.org
}

Award Number: N000141310639

http://www.neaq.org/conservation_and_research/projects/project_pages/right_whale_research.php http://www.neaq.org/conservation_and_research/projects/conservation_medicine/index.php

\section{LONG-TERM GOALS}

Our long-term goal is to broaden the existing panel of endocrine stress assessment techniques for large whales. Few methods exist for assessment of physiological stress levels of free-swimming cetaceans (Amaral 2010, ONR 2010, Hunt et al. 2013). Prior to this grant, we demonstrated that respiratory vapor (blow) sampling is practical and feasible for large whales, and that blow samples contain detectable steroid and thyroid hormones (Hunt et al. 2014). We had also developed a suite of fecal hormone assays for reproductive and stress-related hormones in North Atlantic right whales (NARW; Hunt et al. 2006, Rolland et al. 2005, 2012). However, blow sampling needs further testing before it can enter widespread use, and some additional stress-related hormones have not yet been tested in either feces or blow, particularly the adrenal hormone aldosterone. Our aim in this project is to further develop both techniques - respiratory hormone analysis and fecal hormone analysis - for use in stress assessment of large whales.

\section{OBJECTIVES}

We have two overall objectives in this project: (1) further development of respiratory sampling methodology, via modifications to our sampling apparatus and testing of "internal controls" to control for water content; and (2) development of a noninvasive aldosterone assay (for both feces and blow) that can be used as an alternative measure of adrenal gland activation relative to stress responses, to complement existing glucocorticoid assays.

\section{APPROACH}

Our general approach for FY14 included: (1) fieldwork in the Bay of Fundy for respiratory and fecal sample collection from free-swimming NARW; (2) validation of a novel fecal aldosterone assay and assay of our complete archive of stored individual NARW fecal extracts; (3) completion of the "sampler testing experiment", a major laboratory experiment designed to compare the three most promising respiratory samplers with simulated blow samples (i.e., containing known doses of all 


\section{Report Documentation Page}

Form Approved

OMB No. 0704-0188

Public reporting burden for the collection of information is estimated to average 1 hour per response, including the time for reviewing instructions, searching existing data sources, gathering and maintaining the data needed, and completing and reviewing the collection of information. Send comments regarding this burden estimate or any other aspect of this collection of information,

including suggestions for reducing this burden, to Washington Headquarters Services, Directorate for Information Operations and Reports, 1215 Jefferson Davis Highway, Suite 1204, Arlington

VA 22202-4302. Respondents should be aware that notwithstanding any other provision of law, no person shall be subject to a penalty for failing to comply with a collection of information if it

does not display a currently valid OMB control number.

\begin{tabular}{|c|c|}
\hline $\begin{array}{l}\text { 1. REPORT DATE } \\
\mathbf{0 3} \text { SEP } 2014\end{array}$ & $\begin{array}{l}\text { 3. DATES COVERED } \\
\mathbf{0 0 - 0 0 - 2 0 1 4} \text { to 00-00-2014 }\end{array}$ \\
\hline \multirow{3}{*}{$\begin{array}{l}\text { 4ITLE AND SUBTITLE } \\
\text { Development of Novel Noninvasive Methods of Stress Assessment in } \\
\text { Baleen Whales }\end{array}$} & 5a. CONTRACT NUMBER \\
\hline & 5b. GRANT NUMBER \\
\hline & 5c. PROGRAM ELEMENT NUMBER \\
\hline \multirow[t]{3}{*}{ 6. AUTHOR(S) } & 5d. PROJECT NUMBER \\
\hline & 5e. TASK NUMBER \\
\hline & 5f. WORK UNIT NUMBER \\
\hline $\begin{array}{l}\text { 7. PERFORMING ORGANIZATION NAME(S) AND ADDRESS(ES) } \\
\text { New England Aquarium,Central Wharf,Boston,MA,02110 }\end{array}$ & $\begin{array}{l}\text { 8. PERFORMING ORGANIZATION } \\
\text { REPORT NUMBER }\end{array}$ \\
\hline \multirow[t]{2}{*}{ 9. SPONSORING/MONITORING AGENCY NAME(S) AND ADDRESS(ES) } & 10. SPONSOR/MONITOR'S ACRONYM(S) \\
\hline & $\begin{array}{l}\text { 11. SPONSOR/MONITOR'S REPORT } \\
\text { NUMBER(S) }\end{array}$ \\
\hline
\end{tabular}

12. DISTRIBUTION/AVAILABILITY STATEMENT

Approved for public release; distribution unlimited

13. SUPPLEMENTARY NOTES

14. ABSTRACT

15. SUBJECT TERMS

16. SECURITY CLASSIFICATION OF:

\begin{tabular}{c|c|c|}
$\begin{array}{c}\text { a. REPORT } \\
\text { unclassified }\end{array}$ & $\begin{array}{c}\text { b. ABSTRACT } \\
\text { unclassified }\end{array}$ & $\begin{array}{c}\text { c. THIS PAGE } \\
\text { unclassified }\end{array}$
\end{tabular}

17. LIMITATION OF ABSTRACT

Same as

Report (SAR)

\begin{tabular}{c|l}
$\begin{array}{c}\text { 18. NUMBER } \\
\text { OF PAGES } \\
\mathbf{9}\end{array}$ & 19a. NAME OF \\
& \\
&
\end{tabular}


relevant steroid and thyroid hormones); (4) preliminary investigation into urea assays for potential use as an "internal control", using archived NARW blow samples.

Key individuals in this project are: PI Kathleen Hunt, Ph.D. (fieldwork, analyses, reports and general oversight); Co-PI Rosalind Rolland, D.V.M. (fieldwork, experimental design and data interpretation); Co-PI Scott Kraus, PhD. (right whale biologist, pole design/construction, boat piloting and field logistics); and post-doctoral researcher Elizabeth Burgess, Ph.D. (fieldwork, laboratory analyses, R\&D of novel lab analyses, data interpretation and analysis).

\section{WORK COMPLETED}

\section{Task 1: Fieldwork for Blow Sample Collection}

Based on results of sampler testing experiments (see below) we decided to test two modified sampling apparatuses in the field. The first was a "brideshead" style sampler similar to the type used in our 2011 pilot study but with a different nylon $110 \mu \mathrm{m}$ mesh fabric (Nitrex) that can fit in a $50 \mathrm{ml}$ polypropylene tube (thus simplifying extraction of hormones from the nylon). The second sampler type consists of a square sterile polystyrene plate that can be velcroed to the end of the sampling pole. Twenty-four "Nitrex" bridesheads and twenty-four velcro-plates were prepared for the field season.

Our 2014 field season was originally scheduled to be six weeks long (mid August to late September), including an estimated 15 days at sea. This field season was planned based on historic patterns of NARW abundance in the Bay of Fundy (BOF) in August and September. In 2013, very few whales were sighted in BOF. However, in mid summer 2014 it appeared NARW were returning to the BOF (several dozen whales sighted in the BOF in surface active groups), and consequently we proceeded with the planned field season. R/V Callisto was therefore towed to our field station in Lubec, ME, and four boat crew (Hunt, Burgess, Rolland, Kraus) relocated to Lubec in mid-August. We surveyed the BOF for NARW on five good-weather days (Aug 20, Aug 21, Aug 24, Sep 4, Sep 9), attempting respiratory sampling on all days when NARW were sighted, before deciding to truncate the field season due to low whale abundance (see Results). Additionally, our sister vessel R/V Nereid looked opportunistically for fecal samples from early August to late September, and a colleague's vessel R/V Selkie attempted to collect opportunistic blow samples on two days using a hand-held pole.

\section{Task 2: Labwork}

2a. Sampler testing for blow collection. This experiment was a major focus of our FY2014 effort. This study aimed to: (1) assess whether our three chosen sampling materials cause any interference with assay results; (2) examine whether typical storage conditions of samples in the field (e.g., $6 \mathrm{hr}$ in a cooler with ice packs) cause any degradation in hormone content; and (3) determine the most effective sampling material for the recovery of hormone concentrations from low volume samples (i.e. respiratory vapor).

Three materials were selected as the most promising sampler types for collection of whale respiratory vapor for hormone analysis: 1) commercial nylon veil (previously used successfully in our 2011 pilot study); 2) laboratory-grade nylon $110 \mu \mathrm{m}$ mesh; and 3) polystyrene plate. Our experiment compared recovery of known doses of 6 different hormones in "mock blow solutions" on the three different sampler types, each with eight replications, all subjected to simulated field conditions in the laboratory. "Mock blow solutions" were created by mixing hormone solutions (testosterone, 17 $\beta$-estradiol, progesterone, cortisol, aldosterone, and tri-iodothyronine) at various doses (high $10 \mathrm{ng} / \mathrm{mL}$, medium 1 
$\mathrm{ng} / \mathrm{mL}$ or low $0.1 \mathrm{ng} / \mathrm{mL}$ ) in combinations designed to mimic physiological states of interest: pregnant female, adult male and "stressed whale". Additionally, a control treatment consisted of distilled water only (i.e., no added hormone). Treatment experiments were duplicated for plate samplers to test additional variables specific to plates: (a) method of extracting hormone from flat plates (pipetting off droplets vs. rinsing plates in ethanol); and (b) storage of plates for two weeks in a freezer.

In the experiment, the surface of each sampling material was dripped with an assigned mixed hormone solution or distilled water, and then kept in a cooler on ice packs for $6 \mathrm{~h}$, simulating time on board a boat. After $6 \mathrm{~h}$, hormones were recovered from the samplers, except for an additional set of treated plate samplers which were stored for two weeks at $-20{ }^{\circ} \mathrm{C}$ before hormone extraction. All resulting samples (total $\mathrm{n}=128$ ) were analyzed with commercially available enzyme-immunoassays (EIA) used to quantify progesterone (\#K025-H1), estradiol (\#K036-H1), testosterone (\#K032-H1), cortisol (\#K003-H1) and aldosterone (\#052-H1) concentrations (all EIA kits from Arbor Assays).

Radioimmunoassay was used to quantify triiodothyronine concentrations (\#06B-254215; MP Biomedicals) (Hunt et al. 2014).

2b. Development of an internal control for blow. The bulk of this task is scheduled for FY2015, but in FY2014 we completed pilot trials of two urea assays. These two assays were assessed with a subset of archived individual NARW blow samples from our 2011 pilot study $(\mathrm{n}=19 ; 15$ rinse samples and 4 droplet samples; see Results).

\section{2c. Development of a fecal aldosterone assay:}

During FY2014, we compared 3 different aldosterone kits for parallelism with pooled NARW fecal extract, selected the most sensitive of the three kits, tested accuracy in that kit, and then assayed our entire archive of NARW fecal samples for fecal mineralocorticoids (fMC, e.g. aldosterone and its fecal metabolites). A total of 324 fecal extracts were assayed. The resulting $\mathrm{fMC}$ data were then combined with our existing dataset of other fecal hormones. Analysis is underway regarding correlations with age, sex, reproductive state, season, reproductive steroids (progestins, estrogens, androgens), glucocorticoids and thyroid hormone (see Results).

\section{Task 3: Data Analysis, Manuscript Preparation, and Reporting}

We are well underway with data analysis for both the sampler-testing experiment (task 2a) and fecal aldosterone assay (task 2c), each of which should result in a manuscript. Preliminary results from both experiments were reported at the ONR Program Review in spring 2014, and more detailed analyses of both experiments will be presented at the North Atlantic Right Whale Consortium meeting in November 2014. Manuscripts for both experiments are approximately 50\% completed and we anticipate submission of both manuscripts to peer-reviewed journals sometime in FY2015.

\section{RESULTS}

\section{Task 1: Fieldwork for Blow Sample Collection}

Three fecal samples were collected in early August from the Bay of Fundy. We now have 9 NARW fecal samples awaiting analysis (three from 2014, four from 2013, and two from 2012). These samples will be extracted and assayed for all six hormones (androgens, estrogens, progestins, glucocorticoids, mineralocorticoids, thyroid hormone) in early FY15.

No respiratory samples could be collected this year from the Bay of Fundy due to unusually low whale abundance (see next). 
Low whale abundance in BOF. Normally several hundred NARW occur in the Bay of Fundy in August and September of every year (Hamilton et al. 2007). However, in 2013 only $\sim 1 \%$ of the known population was sighted in the BOF. In early August 2014 it appeared right whales were returning to the BOF, and consequently we planned a full field season. However, by mid August, these NARW retreated from the BOF almost completely. We continued to survey the BOF for NARW with the expectation that they might return, as has happened in previous years. However, after five survey days (Aug 20, Aug 21, Aug 24, Sep 4, Sep 9), NARW abundance remained very low. Additionally, the few NARW sighted were "difficult to work", e.g. surfacing erratically after very long dives. Though every effort was made to follow individual whales for sampling, this erratic surfacing pattern (possibly indicative of low foraging success) prevented us from collecting any respiratory samples. We therefore truncated our planned field season in order to save funds for fieldwork at alternative sites in FY15. Survey tracks of R/V Callisto are presented in Fig. 1.

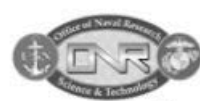

New England Aquarium

August - September 2014

Bay of Fundy Systematic Surveys on $R / V$ Callisto
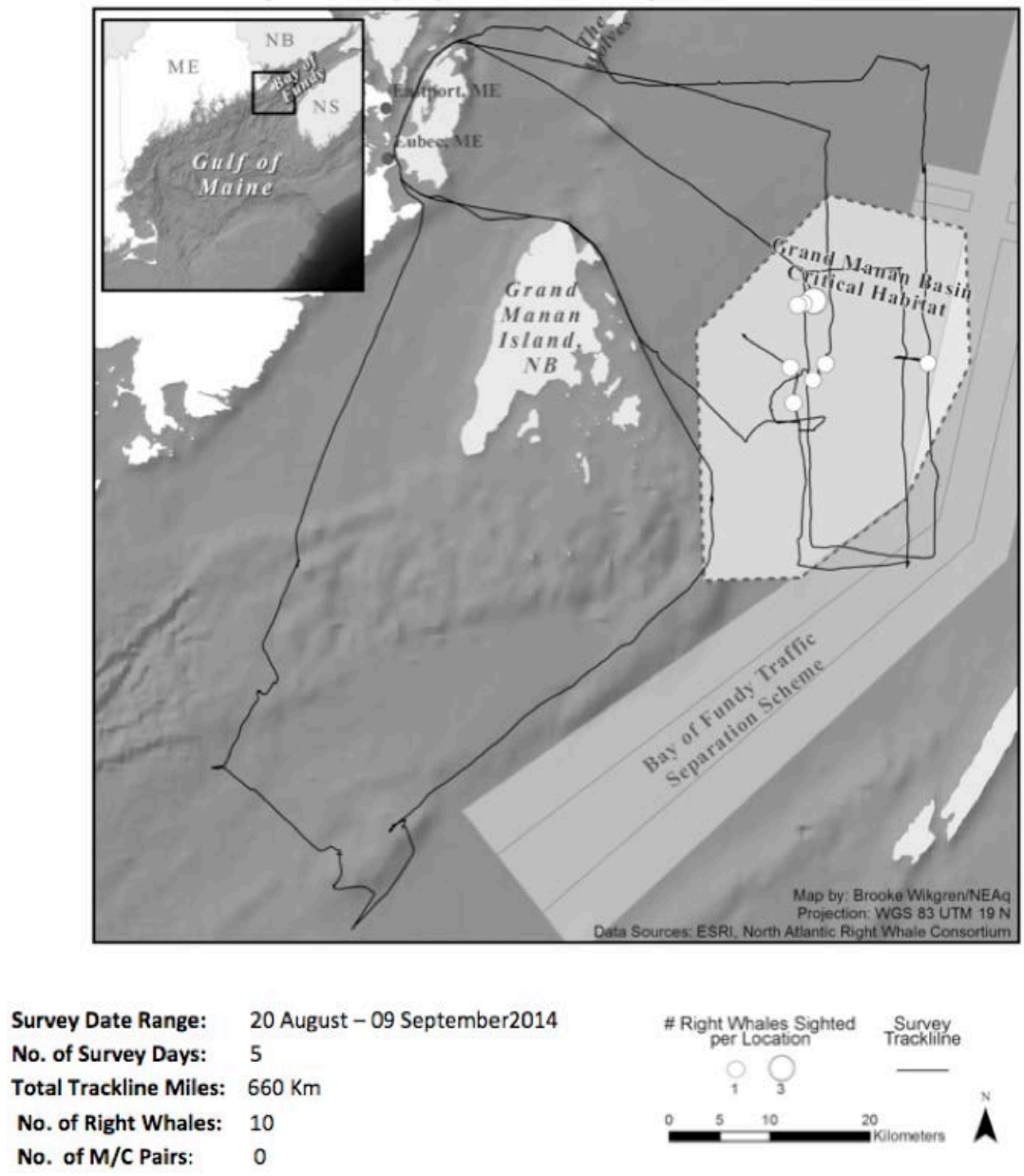

Figure 1. Survey tracks of R/V Callisto in the Bay of Fundy for Aug-Sept 2014. Note the low abundance of North Atlantic right whales (white circles). 


\section{Task 2: Labwork}

2a. Sampler testing for blow.

Results showed that all three sampling materials (commercial veil, laboratory-grade mesh and polystyrene plate) are potentially viable for sampling hormones collected from whale blow (Fig. 2). Extraction methods for all sampler types yielded consistent and repeatable results across all measured hormones, as indicated by low standard deviations. Notably, the plate sampler required a full ethanol rinse for efficient hormone extraction (i.e. direct pipetting off the plate was insufficient), particularly for the recovery of progesterone. Furthermore, the veil and mesh materials exhibited mild 'non-zero' background levels in some hormone assays. Storing samples for $6 \mathrm{~h}$ in a cooler appeared not to affect any of the six hormones under study, which verifies that basic field storage conditions (e.g., thickwalled cooler with ice packs) are adequate for this type of sample collection. The additional 2-week storage experiment also showed that plate samplers could also be stored frozen for an extended period before extraction. Importantly, expected hormone ratios (i.e. low/high levels) could be correctly identified for all hormones measured in each sampler type - that is, even in cases were absolute values deviated from the expected results, relative patterns and ratios were consistent.

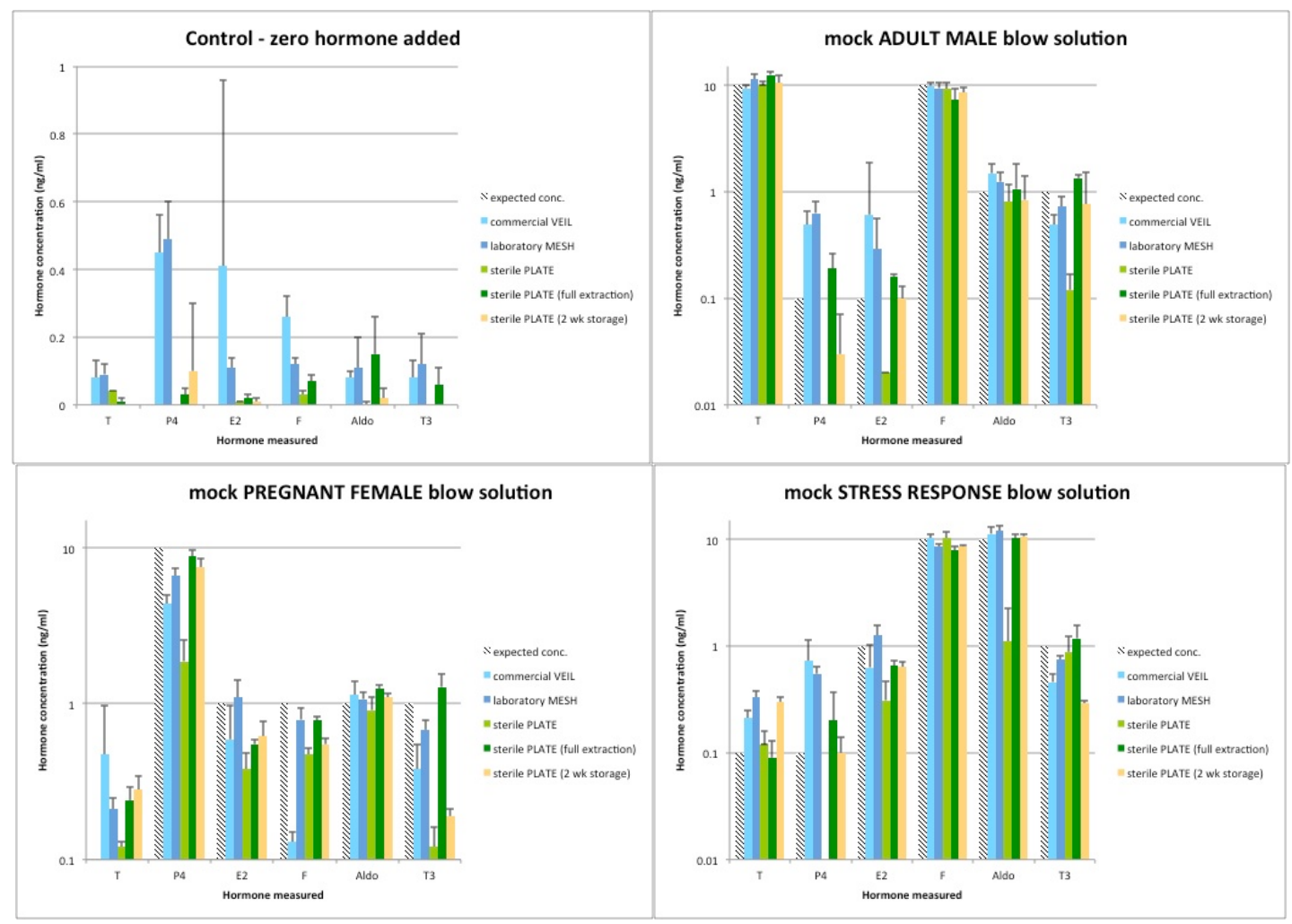

Figure 2. Results of measured hormone concentrations $(\mathrm{ng} / \mathrm{ml} \pm \mathrm{SD})$ extracted from each sampler type (veil, mesh, plate) in each treatment (control, male, female, stress response) spiked with low (0.1 $\mathrm{ng} / \mathrm{ml})$, medium $(1.0 \mathrm{ng} / \mathrm{ml})$ and high $(10 \mathrm{ng} / \mathrm{ml})$ concentrations of various hormones (T, P4, E2, F, Aldo, T3).

\section{2b. Development of an internal control for blow.}

We conducted initial testing of urea as a potential "internal control" for blow samples. Using a pool created from the largest NARW blow samples $(n=10)$ collected in 2011 , we tested parallelism of 
serially diluted sample to the standard curve for two urea assays: 1) urea nitrogen (BUN) detection kit (\#K024-H1, Arbor Assays); and 2) QuantiChrom ${ }^{\mathrm{TM}}$ urea assay kit (\#50-489-225, Bioassay Systems). The Arbor Assays kit was further tested by assaying 19 individual archived NARW blow samples $(\mathrm{n}=$ 15 rinse samples and 4 droplet samples. Parallelism was good and urea was detected in all samples, providing evidence that urea may hold promise as an internal control (Fig. 3).
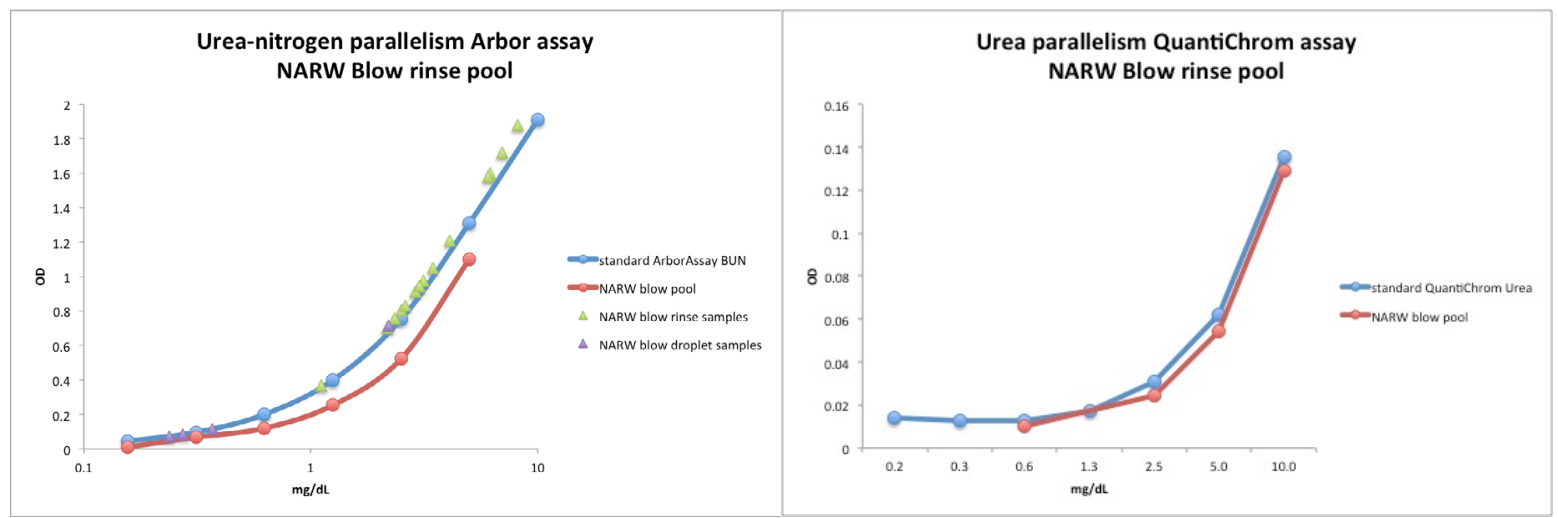

Figure 3. Parallelism results for two urea assay kits tested with the same NARW fecal pool. Note parallelism of standards (blue lines) with serially diluted $N A R W$ fecal extract (red lines).

\section{2c. Development of a fecal aldosterone assay.}

Three commercial aldosterone assays for testing (selected based on manufacturer's reported precision, reliability, and sensitivity): (1) Alpco EIA \#11-ALDHU-E01, (2) Creative Diagnostics \#DEIA4474, and Siemens Coat-a-Count 125I RIA \#TKAL1. All three kits were tested for parallelism with a pooled NARW fecal extract derived from high-glucocorticoid fecal samples. All three kits demonstrated good parallelism (Fig. 4), indicating that fMCs are present and detectable in NARW fecal extracts.
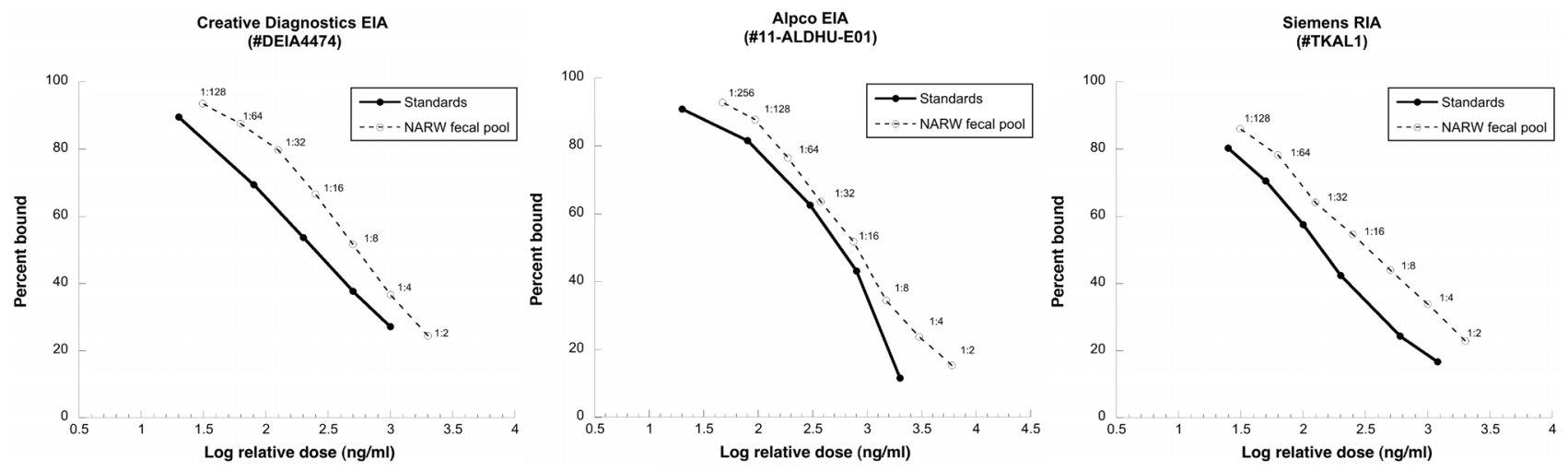

Figure 4. Parallelism results for three aldosterone assay kits tested with the same NARW fecal pool. Note parallelism of standards (solid lines) with serially diluted $N A R W$ fecal extract (dashed lines).

Of the three kits, the Siemens RIA had slightly superior parallelism and also had best sensitivity. We therefore tested this kit further for accuracy, spiking a set of standards with NARW fecal extract and running them alongside unspiked standards, and assessing results (graphed as apparent vs. known dose 
of the spiked standards) for straightness and slope. The Siemens kit exhibited superb accuracy, with a straight line with a slope very close to 1.0 (slope was 0.93 ; Fig. 5). In addition to excellent accuracy and parallelism, this kit was also cheapest. Therefore the Siemens kit was selected for assaying of all individual NARW fecal extracts.

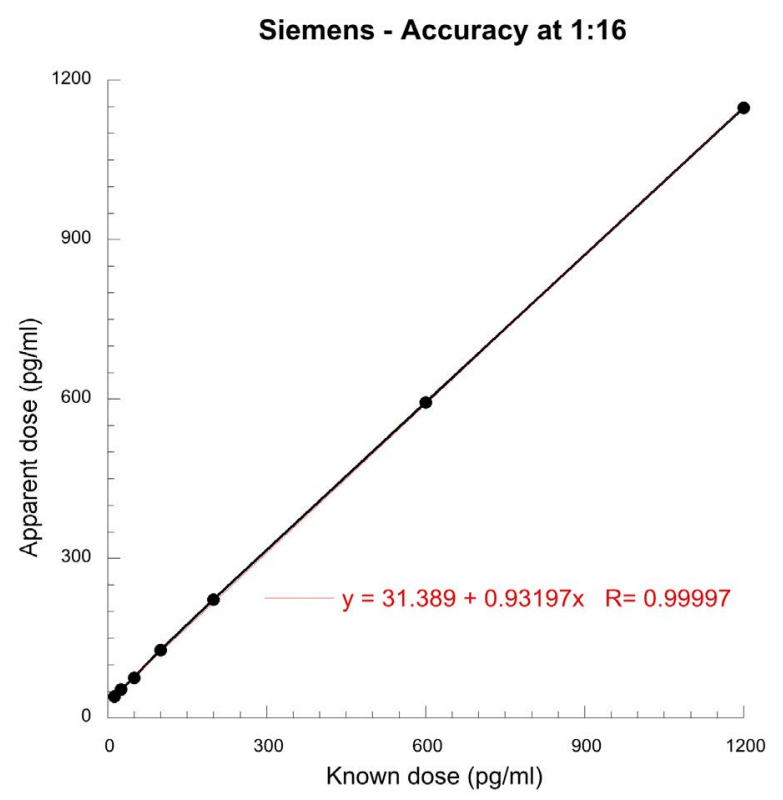

Figure 5. Accuracy results for the Siemens RIA aldosterone kit tested with NARW fecal extract at a dilution of 1:16 in assay buffer. Note straightness of line with slope close to 1.0, indicating good mathematical accuracy across a range of doses.

We assayed a total of 324 fecal extracts for fMCs with the Siemens aldosterone kit, using extracts prepared in a previous ONR-funded study (ONR award \#N000141010614). Our first analysis of the resulting data focused on delineation of normal ranges of $\mathrm{fMC}$ for different NARW classes (age, sex, reproductive state). For this analysis we restricted our dataset to samples that met the following criteria: species identification was certain, sex and reproductive state known from sightings records (rather than inferred from other fecal steroids), animals alive and not entangled, and older than calves (since calves may ingest maternal steroids via milk fat). Our final data set for this analysis consisted of 98 samples of six different age/sex/state categories (Table 1). Note that "resting" females refers to mature females that are neither pregnant nor lactating.

Table 1. Sample sizes of $N A R W$ age/sex/state categories used in initial statistical analyses of fecal mineralocorticoid data.

\begin{tabular}{|l|l|}
\hline NARW Category: & n \\
\hline Immature Males & 10 \\
\hline Immature Females & 16 \\
\hline Mature Males & 24 \\
\hline Resting Females & 17 \\
\hline Lactating Females & 21 \\
\hline Pregnant Females & 10 \\
\hline Total & $\mathbf{9 8}$ \\
\hline
\end{tabular}


Like most other hormones we have studied in NARW, fMC varied significantly with reprodutive state (Fig. 6). Pregnant females had significantly higher fMC than all other categories of NARW (KruskalWallis test, $\mathrm{P}<0.0001, \mathrm{KW}=40.866$; post-hoc testing with Dunn's multiple comparisons test and alpha $=0.05$ ). The inclusion of pregnant females skewed the dataset markedly due to high fMC values. If pregnant females are excluded from the analysis, mature males have higher significantly fecal aldosterone than three other classes of NARW: immature females, immature males and resting females (Kruskal-Wallis test, $\mathrm{P}=0.0005, \mathrm{KW}=20.195$; post-hoc testing with Dunn's multiple comparisons test and alpha $=0.05)$.

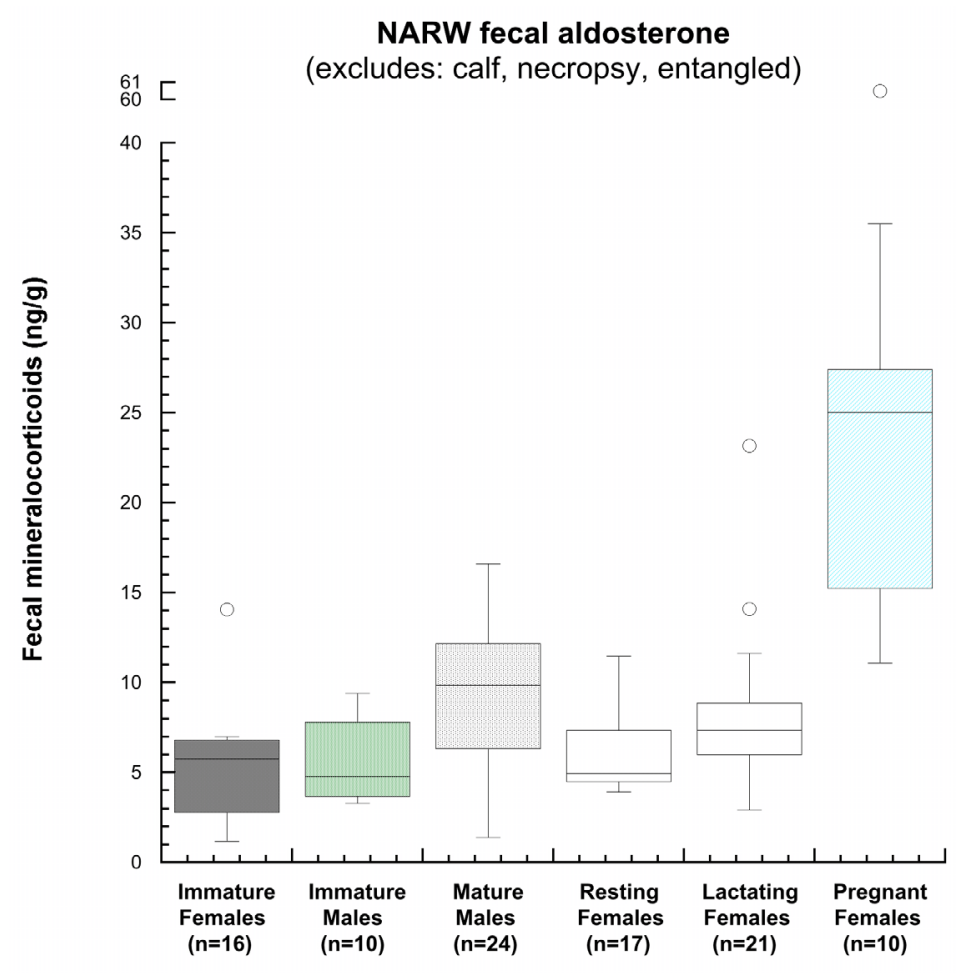

Figure 6. Boxplots of fecal mineralocorticoid data relative to NARW category (age, sex, state).

In sum, fecal mineralocorticoids are present and detectable in NARW feces with a variety of commercial kits, and data show significant differences between age/sex/state categories. Further analyses, including correlations to other hormones, are ongoing.

\section{IMPACT/APPLICATIONS}

We have completed the first rigorous, controlled analysis of hormone recovery from respiratory sampling devices; to our knowledge nobody has performed these validations before for any hormone for any respiratory sampling device in whales. We have also demonstrated that fecal mineralocorticoid (e.g. aldosterone) is present and measurable in right whale feces, and that it shows significant differences between different ages, sex, and reproductive states. Aldosterone may therefore be a useful complement to existing measures for assessing acute and chronic stress in whales. The work described here may add to the tools needed to evaluate the physiologic consequences of different noise levels on one species of baleen whale, and may serve as a model for other marine species. 


\section{RELATED PROJECTS}

No related projects.

\section{REFERENCES}

Amaral RS. 2010. Use of alternative matrices to monitor steroid hormones in aquatic mammals: a review. Aquatic Mammals 36:162-171.

Hamilton PK, Knowlton AR, Marx MK. 2007. Right whales tell their own stories: The photoidentification catalog. Pages 75-104 in: Kraus SD and Rolland RM (eds.) The Urban Whale: North Atlantic right whales at the crossroads. Harvard University Press, Cambridge, MA.

Hunt KE, Wasser SK. 2003. Effect of long-term preservation methods on fecal glucocorticoid concentrations of grizzly bear and African elephant. Physiological and Biochemical Zoology 76:918-928.

Hunt KE, Rolland RM, Kraus SD, Wasser SK. 2006. Analysis of fecal glucocorticoids in the North Atlantic right whale (Eubalaena glacialis) using high-performance liquid chromatography (HPLC). General and Comparative Endocrinology 148:260-272.

Hunt KE, Moore MJ, Rolland RM, Kellar NM, Hall AJ, Kershaw J, Raverty SA, Davis CE, Yeates LC, Fauquier DA, Rowles TK, Kraus SD. 2013. Overcoming the challenges of studying conservation physiology in large whales: a review of available methods. Conservation Physiology $1: \cot 006$.

Hunt KE, Rolland RM, Kraus SD. 2014. Detection of steroid and thyroid hormones via immunoassay of North Atlantic right whale (Eubalaena glacialis) respiratory vapor. Marine Mammal Science 30(2):796-809.

Office of Naval Research. 2010. Final Workshop Proceedings, "Effects of Stress of Marine Mammals Exposed To Sound", Arlington, VA; meeting dates 4-5 November 2009.

Rolland RM, Hunt KE, Kraus SD,Wasser SK. 2005. Assessing reproductive status of right whales (Eubalaena glacialis) using fecal hormone metabolites. General and Comparative Endocrinology 142:308-317.

Rolland RM, Parks SE, Hunt KE, Castellote M, Corkeron PJ, Nowacek DP, Wasser SK, Kraus SD. 2012. Evidence that ship noise increases stress in right whales. Proceedings of the Royal Society B 279:2363-2368. 